\title{
Mediation of contraction in rat cauda epididymidis by alpha-adrenoceptors
}

\author{
G. Chaturapanich, S. Maythaarttaphong, V. Verawatnapakul \\ and C. Pholpramool* \\ Department of Physiology, Faculty of Science, Mahidol University, Rama VI Road, \\ Bangkok 10400, Thailand
}

\begin{abstract}
Subtypes of alpha-adrenoceptors responsible for contractions of the rat cauda epididymidis were studied in vivo by micropuncture using a servo-nulling pressure transducer system. Administration of both non-selective and selective alpha-adrenoceptor agonists in doses of 1-40 $\mu$ g noradrenaline $\mathrm{kg}^{-1}$ body weight (BW), 1-100 $\mu \mathrm{g}$ clonidine $\mathrm{kg}^{-1} \mathrm{BW}$, or 100-800 $\mu$ g methoxamine $\mathrm{kg}^{-1} \mathrm{BW}$ enhanced contractions of the proximal cauda epididymidis in a dose-response manner. The potency of the agonists were noradrenaline $\geqslant$ clonidine $>$ methoxamine. Pretreatments with selective $\alpha_{1}$-adrenoceptor antagonist
\end{abstract}

(prazosin) and $\alpha_{2}$-adrenoceptor antagonist (yohimbine) at the doses of 400 and $800 \mu \mathrm{g} \mathrm{kg}^{-1} \mathrm{BW}$, respectively, had very little effect on spontaneous contractions, but effectively blocked the responses to the maximal doses of methoxamine and clonidine. The responses could not be explained by the systemic effects of agonists and antagonists. The results suggest that contraction of the proximal cauda epididymidis of rats is mediated by both $\alpha_{1}$ - and $\alpha_{2}$-adrenoceptors. The latter appears to be more abundant.

\section{Introduction}

Mammalian spermatozoa produced in the testis move through the excurrent ducts largely as a consequence of the inherent contractility of the smooth muscle surrounding the ducts. The epididymis is of critical importance in this regard as it is the site of sperm maturation and storage (Cooper, 1986). Spermatozoa from different species exhibit a characteristic transit time through the epididymis, for example 18 days in bulls (Koefoed-Johnsen, 1960), 10 days in mice (Meistrich et al., 1975), and 8 days in rats (Sujarit and Pholpramool, 1985). Disruption of sperm transit affects sperm maturation (Cummins, 1976) and fertility (Ratnasooriya and Wadsworth, 1990; Ricker et al., 1997).

Contraction of the epididymal duct is under the control of autonomic nerves (El-Badawi and Schenk, 1967; Hodson, 1970) and androgens (Hib and Ponzio, 1977; Din-Udom et al., 1985). Although both cholinergic and adrenergic terminals are present, adrenergic agonists appear to be more potent than cholinergic agonists in enhancing the spontaneous contractions (Hib, 1976; Laitinen and Talo, 1981; Pholpramool and Triphrom, 1984; Ricker and Chang, 1996). The effect of the adrenergic agonists occurs primarily through activation of alphaadrenoceptors (Pholpramool and Triphrom, 1984). In vitro

*Correspondence

Email: sccpp@mahidol.ac.th studies using field stimulation revealed the presence of both $\alpha_{1}$ - and $\alpha_{2}$-adrenoceptors in the cauda epididymidis of guinea-pigs (Haynes and Hill, 1996) and vas deferens of rats (Ventura and Pennefather, 1994). However, the cauda epididymidis of rats lacks $\alpha_{2}$-adrenoceptors (Ventura and Pennefather, 1991, 1994). Whether this discrepancy is due to species difference is uncertain at present. As it is known that $\alpha_{2}$-adrenoceptors on nerve terminals play an important role in the regulation of noradrenaline release, it is of interest to determine the subtype of adrenoceptors in the proximal regions of the epididymis. The aim of this study was to identify the adrenoceptor subtypes in the proximal cauda epididymidis of rats by micropuncture technique in vivo using a servo-nulling pressure measuring system.

\section{Materials and Methods}

\section{Chemicals}

Noradrenaline, methoxamine, clonidine, prazosin and yohimbine were purchased from Sigma Chemical Company (St Louis, MO).

\section{Animals}

Sexually mature male Wistar rats (250-350 g) were obtained from the National Laboratory Animal Centre at Salaya Campus, Mahidol University. They were housed under $12 \mathrm{~h}$ light : $12 \mathrm{~h}$ dark cycle, and were provided with laboratory rat chow and tap water ad libitum. All 
experiments were carried out according to the International Guiding Principles for Biomedical Research Involving Animals of CIOMS. All of the experiments have been reviewed and approved by the Mahidol University research project reviewer committee.

The rats were fasted overnight and anaesthetized by an intraperitoneal injection of sodium pentobarbital (Nembutal: Sanofi Sante Animale SA, Paris) at a dose of $50 \mathrm{mg} \mathrm{kg}^{-1}$ body weight (BW). Tracheostomy was performed to ensure a clear airway passage. The right external jugular vein and left carotid artery were catheterized with polyethylene tubing (PE 50: Clay-Adams) for injections of drugs and for continuous recording of systemic blood pressure, respectively. Body temperature of the animals was maintained at $37^{\circ} \mathrm{C}$ by a heating lamp connected to a temperature control unit ( $\mathrm{YSI}$ model 73A) with a rectal probe. At the conclusion of all of the experiments, animals were killed by an overdose of sodium pentobarbital.

\section{Micropuncture and measurement of intraluminal pressures}

The testis and the epididymis were prepared for micropuncture and intraluminal pressure measurements according to Pholpramool et al. (1984). The bath temperature was set at $34^{\circ} \mathrm{C}$. The pressure measurements in the epididymis were performed at site 6 of the proximal cauda epididymidis according to Hinton et al. (1979). The parameters measured in this study were (i) intraluminal pressure, which includes basal pressure, amplitude of contraction and total pressure, and (ii) frequency of contractions. Basal pressure is defined as the pressure in the tubule during the quiescent state as reflected by sustained hydrostatic pressure; amplitude of contraction is the pressure generated by rhythmic contraction of the tubule; and total pressure is the sum of basal pressure and amplitude of contraction (Pholpramool et al., 1984).

\section{Experiment 1: Effects of alpha-adrenoceptor agonists} on the intraluminal pressure of the cauda epididymidis

The aim of this experiment was to test whether contractions of the epididymis are mediated through $\alpha_{1}$ or $\alpha_{2}$-adrenoceptors using noradrenaline (non-selective adrenoceptor agonist), methoxamine ( $\alpha_{1}$-adrenoceptor agonist), and clonidine ( $\alpha_{2}$-adrenoceptor agonist). A total of 43 rats was divided into three groups: noradrenaline-treated (16 rats), methoxamine-treated (12 rats) and clonidinetreated (15 rats) groups. The surface tubule of the cauda epididymidis was punctured and intraluminal pressure was recorded continuously. After a steady intraluminal pressure was established and recorded as control for approximately 5 min, doses of alpha-adrenoceptor agonist were administered. In each group, two or three doses of an agonist were given intravenously in an increasing order to obtain a dose-response curve.
Experiment 2: Effect of alpha-adrenoceptor antagonists on the contraction of the cauda epididymidis

This experiment was conducted to test the effectiveness of different specific antagonists in blocking the responses of the epididymis to the maximum doses of various agonists. Twenty rats were divided into four equal groups. The first two groups were used to study the effects of prazosin $\left(400 \mu \mathrm{g} \mathrm{kg}^{-1}\right.$ $\mathrm{BW})$ or yohimbine (800 $\left.\mu \mathrm{g} \mathrm{kg}^{-1} \mathrm{BW}\right)$ on contraction response to noradrenaline. The third and fourth groups were used to study the effects of prazosin or yohimbine on the contraction response to methoxamine and clonidine, respectively. The doses of the alpha-andrenoceptor antagonists used in this study had been shown to be effective in preliminary experiments. The experimental procedure was similar to that described in Expt 1 except that the alpha-adrenoceptor antagonist was injected intravenously approximately $1 \mathrm{~min}$ before administration of the maximal dose of adrenergic agonist (dosage obtained from Expt 1).

\section{Statistical analysis}

All data are presented as means and standard errors of the means (mean \pm SEM). Statistical analyses were performed using SPSS program, release 7.5.1. For comparison between different groups (in Expt 1), ANOVA was performed if the data were normally distributed and had equal variance. When tests of either normality or equal variance failed, non-parametric Kruskal-Wallis ANOVA on ranks was performed. The repeated measures design was used to test differences within experimental groups (in Expt 2). The critical probability for rejection of the null hypothesis was 0.05 throughout.

\section{Results}

Effects of alpha-adrenoceptor agonists on intraluminal pressure of the cauda epididymidis

Representative records of the contraction of the epididymis in response to adrenergic agonists are illustrated (Fig. 1). All three agonists enhanced the spontaneous contraction by increasing the frequency with or without increasing the amplitude, thus resulting in an increase in basal pressure. The responses were generally followed by a pause of contraction for a varying period before regular activity resumed.

Dose-response curves of noradrenaline, methoxamine and clonidine on intraluminal pressure and frequency of contraction of the cauda epididymidis are shown (Fig. 2). It is apparent that noradrenaline is the most potent of the three agonists. A significant increase in the frequency of contraction was noted with noradrenaline at a dose as low as $1 \mu \mathrm{g} \mathrm{kg}^{-1} \mathrm{BW}$. The dose-response curve of noradrenaline was biphasic with the maximum effect at the dose of $20 \mu \mathrm{g} \mathrm{kg}{ }^{-1}$ BW. Methoxamine was the least potent adrenoceptor agonist. Doses of 100 and $200 \mu \mathrm{g} \mathrm{kg}^{-1} \mathrm{BW}$ had virtually no effect on contraction of the epididymis. 

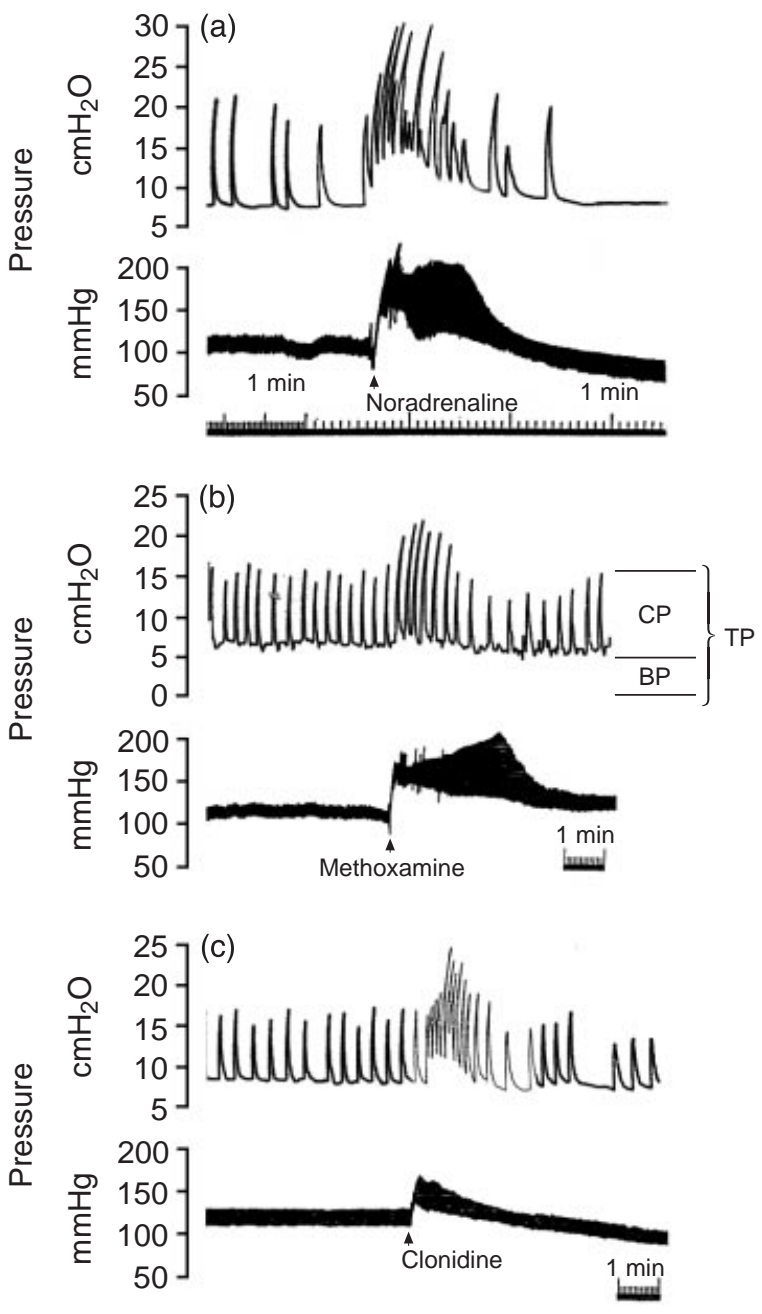

Fig. 1. Effects of (a) noradrenaline $\left(20 \mu \mathrm{g} \mathrm{kg}{ }^{-1}\right.$ body weight (BW)), (b) methoxamine (400 $\left.\mu \mathrm{g} \mathrm{kg}^{-1} \mathrm{BW}\right)$ and (c) clonidine $(10 \mu \mathrm{g} \mathrm{kg}-1$ $\mathrm{BW}$ ) on the intraluminal pressures (upper tracing) and arterial blood pressure (lower tracing) of the cauda epididymidis. BP: basal pressure; CP: contractile pressure or amplitude of contraction; TP: total pressure.

Significant increases in the basal and total pressures, and the amplitude and frequency of contractions were observed only after doses of 400 and $800 \mu \mathrm{g} \mathrm{kg}^{-1}$ BW. Clonidine at a dose of $1 \mu \mathrm{g} \mathrm{kg}^{-1} \mathrm{BW}$ increased the frequency without affecting the amplitude of contraction. However, higher doses did not increase the frequency or intraluminal pressure further. Overall, the relative potency of the adrenoceptor agonists used in this study was: noradrenaline $\geqslant$ clonidine $>$ methoxamine.

After administration of noradrenaline $\left(20 \mu \mathrm{g} \mathrm{kg}^{-1} \mathrm{BW}\right)$ and methoxamine $\left(400 \mu \mathrm{g} \mathrm{kg}^{-1} \mathrm{BW}\right)$, the arterial blood pressure increased significantly from $107.0 \pm 2.7$ to $155.9 \pm 2.9 \mathrm{mmHg} \quad(n=15)$ and from $108.6 \pm 2.7$ to $153.2 \pm 2.5 \mathrm{mmHg} \quad(n=11)$, respectively. In contrast, clonidine $\left(10 \mu \mathrm{g} \mathrm{kg}{ }^{-1} \mathrm{BW}\right)$ significantly reduced arterial blood pressure by nearly half of the control value from $103.3 \pm 2.8$ to $58.3 \pm 3.2 \mathrm{mmHg}(n=8)$.
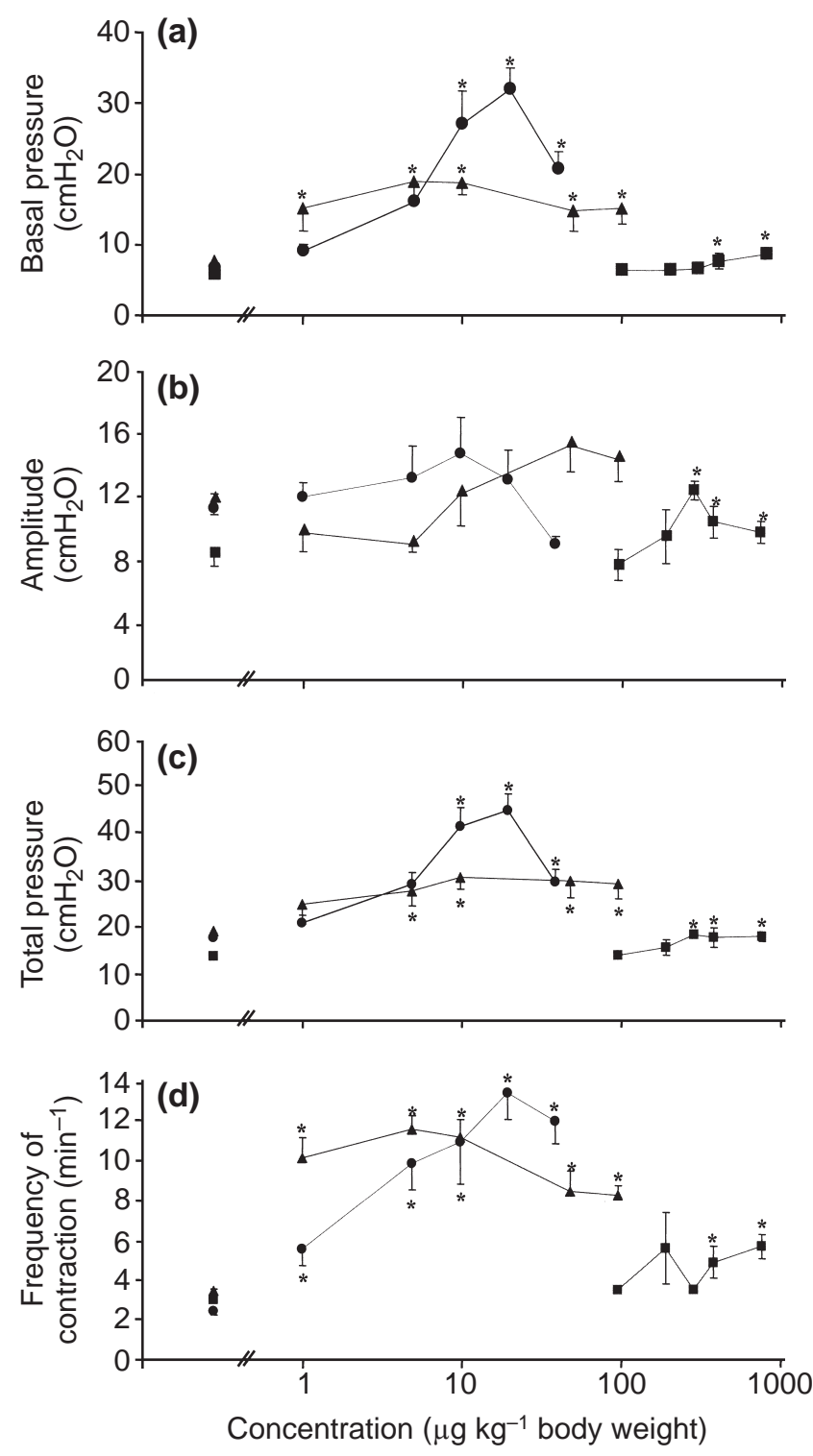

Fig. 2. Dose-response curves of noradrenaline (-), methoxamine ( $\boldsymbol{\square})$ and clonidine ( $\boldsymbol{\Delta}$ ) on (a) intraluminal basal pressure, (b) amplitude of contraction, (c) total intraluminal pressure and (d) frequency of contraction of rat cauda epididymidis. Each data point represents mean \pm SEM of six to nine rats (noradrenaline), five or six rats (methoxamine) or five to seven rats (clonidine). $* P<0.05$ compared with control values.

Effects of alpha-adrenoceptor antagonists on intraluminal pressure of the cauda epididymidis

The selective alpha-adrenoceptor antagonists prazosin $\left(400 \mu \mathrm{g} \mathrm{kg}^{-1} \mathrm{BW}\right)$ or yohimbine $\left(800 \mu \mathrm{g} \mathrm{kg}{ }^{-1} \mathrm{BW}\right)$ given alone did not affect the intraluminal pressure or spontaneous contraction of the cauda epididymidis (Tables 1, 2 and 3). However, pretreatment with either prazosin or yohimbine significantly reduced the response to noradrenaline $\left(20 \mu \mathrm{gg}^{-1} \quad \mathrm{BW}\right.$; Table 1). Prazosin 
Table 1. Effects of prazosin $\left(400 \mu \mathrm{g} \mathrm{kg}{ }^{-1} \mathrm{BW}\right)$ and yohimbine $\left(800 \mu \mathrm{g} \mathrm{kg}^{-1} \mathrm{BW}\right)$ on contraction of the rat cauda epididymidis in response to noradrenaline $\left(20 \mu \mathrm{g} \mathrm{kg}^{-1} \mathrm{BW}\right)$

\begin{tabular}{|c|c|c|c|c|}
\hline \multirow[b]{2}{*}{ Treatment } & \multicolumn{3}{|c|}{ Intraluminal pressure $\left(\mathrm{cmH}_{2} \mathrm{O}\right)$} & \multirow{2}{*}{$\begin{array}{c}\text { Frequency of } \\
\text { contraction }\left(\mathrm{min}^{-1}\right)\end{array}$} \\
\hline & Basal pressure & Amplitude of contraction & Total pressure & \\
\hline Control & $5.2 \pm 0.5$ & $8.8 \pm 1.0$ & $14.0 \pm 1.0$ & $2.6 \pm 0.2$ \\
\hline Noradrenaline & $17.9 \pm 3.5^{*}$ & $9.3 \pm 1.6$ & $27.2 \pm 2.7^{*}$ & $14.2 \pm 1.8^{*}$ \\
\hline Prazosin & $4.7 \pm 1.0^{+}$ & $8.3 \pm 1.1$ & $13.0 \pm 1.5^{+}$ & $4.6 \pm 1.0^{+}$ \\
\hline $\mathrm{NA}+$ prazosin & $11.8 \pm 1.2^{*+}$ & $8.9 \pm 1.5$ & $20.7 \pm 2.1^{*+}$ & $9.2 \pm 1.3^{*+}$ \\
\hline Control & $5.4 \pm 0.4$ & $8.0 \pm 0.5$ & $13.4 \pm 0.4$ & $2.4 \pm 0.2$ \\
\hline Noradrenaline & $15.8 \pm 1.9^{*}$ & $8.5 \pm 1.4$ & $24.3 \pm 2.2^{*}$ & $12.6 \pm 2.1^{*}$ \\
\hline Yohimbine & $5.9 \pm 0.6^{+}$ & $6.9 \pm 0.4$ & $12.8 \pm 0.8^{+}$ & $4.8 \pm 1.7^{\dagger}$ \\
\hline $\mathrm{NA}+$ yohimbine & $8.1 \pm 0.5^{*+}$ & $6.1 \pm 0.4$ & $14.2 \pm 0.5^{+}$ & $4.8 \pm 0.7^{+}$ \\
\hline
\end{tabular}

Values are mean \pm SEM. $n=5$ rats per group.

NA: noradrenaline.

*Significantly different from control $(P<0.05)$.

${ }^{+}$Significantly different from noradrenaline $(P<0.05)$.

Table 2. Effect of prazosin $\left(400 \mu \mathrm{g} \mathrm{kg}{ }^{-1} \mathrm{BW}\right)$ on the contraction of the rat cauda epididymidis in response to methoxamine $\left(400 \mu \mathrm{g} \mathrm{kg}{ }^{-1} \mathrm{BW}\right)$

\begin{tabular}{lcccc}
\hline & \multicolumn{3}{c}{ Intraluminal pressure $\left(\mathrm{cmH}_{2} \mathrm{O}\right)$} & Frequency of \\
\cline { 2 - 4 } Treatment & Basal pressure & Amplitude of contraction & Total pressure & contraction $\left(\right.$ min $\left.^{-1}\right)$ \\
\hline Control & $4.8 \pm 0.2$ & $7.0 \pm 0.3$ & $11.8 \pm 0.2$ & $3.0 \pm 0.1$ \\
Methoxamine & $5.8 \pm 0.3^{*}$ & $13.4 \pm 1.9^{*}$ & $19.2 \pm 1.8^{*}$ & $4.0 \pm 0.3^{*}$ \\
Prazosin & $4.8 \pm 0.1^{+}$ & $5.8 \pm 0.4^{+}$ & $10.6 \pm 0.4^{+}$ & $3.0 \pm 0.3^{+}$ \\
Methoxamine + prazosin & $4.7 \pm 0.1^{+}$ & $5.4 \pm 0.4^{+}$ & $10.1 \pm 0.3^{+}$ & $3.0 \pm 0.3^{+}$ \\
\hline
\end{tabular}

Values are mean \pm SEM. $n=5$ rats per group.

*Significantly different from control $(P<0.05)$.

${ }^{\dagger}$ Significantly different from methoxamine $(P<0.05)$.

Table 3. Effect of yohimbine $\left(800 \mu \mathrm{g} \mathrm{kg}^{-1} \mathrm{BW}\right)$ on the contraction of the rat cauda epididymidis in response to clonidine $\left(10 \mu \mathrm{g} \mathrm{kg}{ }^{-1} \mathrm{BW}\right)$

\begin{tabular}{lcccc}
\hline & \multicolumn{3}{c}{ Intraluminal pressure $\left(\mathrm{cmH}_{2} \mathrm{O}\right)$} & \multicolumn{1}{c}{$\begin{array}{c}\text { Frequency of } \\
\text { Treatment }\end{array}$} \\
\cline { 2 - 5 } & Basal pressure & Amplitude of contraction & Total pressure & \\
\hline Control & $7.2 \pm 0.4$ & $10.5 \pm 0.8$ & $17.7 \pm 0.9$ & $3.5 \pm 0.1$ \\
Clonidine & $19.0 \pm 2.3^{*}$ & $8.8 \pm 0.5$ & $27.8 \pm 2.5^{*}$ & $12.0 \pm 0.9^{*}$ \\
Yohimbine & $7.3 \pm 0.8^{+}$ & $10.6 \pm 1.9$ & $17.9 \pm 2.2^{+}$ & $2.8 \pm 0.5^{+}$ \\
Clonidine + yohimbine & $7.7 \pm 0.7^{+}$ & $9.3 \pm 0.6$ & $17.0 \pm 0.9^{+}$ & $2.6 \pm 0.7^{+}$ \\
\hline
\end{tabular}

Values are mean \pm SEM. $n=5$ rats per group.

*Significantly different from control $(P<0.05)$.

${ }^{+}$Significantly different from clonidine $(P<0.05)$.

pretreatment abolished the weak response of the cauda epididymidis to methoxamine $\left(400 \mu \mathrm{g} \mathrm{kg}^{-1}\right.$ BW; Table 2) and yohimbine pretreatment abolished the response to clonidine $\left(10 \mu \mathrm{g} \mathrm{kg}^{-1} \mathrm{BW}\right.$; Table 3$)$.

Concomitant with the effect on the intraluminal pressure, $400 \mu \mathrm{g}$ prazosin $\mathrm{kg}^{-1}$ BW decreased arterial blood pressure by $23 \%$ (from $104.9 \pm 2.5 \mathrm{mmHg}$ to $80.8 \pm 2.3 \mathrm{mmHg}$, $n=6$ ) whereas $800 \mu \mathrm{g}$ yohimbine $\mathrm{kg}^{-1} \mathrm{BW}$ increased the blood pressure $(P<0.05)$ by $36 \%$ (from $102.0 \pm 2.0 \mathrm{mmHg}$ to $138.3 \pm 2.1 \mathrm{mmHg}, n=6$ ).

\section{Discussion}

The results of the present study demonstrated that intraluminal pressure and frequency of contractions in the rat cauda epididymidis were increased after 
administration of alpha-adrenoceptor agonists. The potency of alpha-adrenoceptor agonists was in the following order: noradrenaline (non-selective $\alpha_{1}$-adrenoceptor agonist) $\geqslant$ clonidine $\left(\alpha_{2}\right.$-adrenoceptor agonist $)>$ methoxamine $\left(\alpha_{1}\right.$ adrenoceptor agonist). This result is consistent with the report of Ventura and Pennefather (1991). It was also shown that contraction of the cauda epididymidis in response to noradrenaline was decreased by both prazosin and yohimbine, the latter of which resulted in a complete blockage. In addition, prazosin and yohimbine prevented contraction induced by methoxamine or clonidine, respectively. These results could not be attributed to the concomitant changes in systemic arterial blood pressure. However, the possible influence of the reflex autonomic nerve activity induced by the drugs could not be entirely eliminated. As the doses of both agonists and antagonists were pharmacological, the effect of changes in the intrinsic nerve activity, if any, would be small. The results on the effects of alpha-adrenoceptor agonists and antagonists on contraction of the rat cauda epididymidis were consistent with the previous reports of $\alpha_{1}$-adrenoceptors in rat epididymis (Pholpramool and Triphrom, 1984; QueirozNeto and Ballejo, 1993; Ventura and Pennefather (1991); and $\alpha_{1}$-and $\alpha_{2}$-adrenoceptors in the cauda epididymidis of guinea-pigs (Haynes and Hill, 1996). However, Ventura and Pennefather (1994) were unable to demonstrate the presence of $\alpha_{2}$-adrenoceptors in rat cauda epididymidis using $\left[{ }^{3} \mathrm{H}\right]$ rauwolscine-specific binding and functional study of electrical stimulation in vitro. This discrepancy may be due to regional differences in the epididymis as well as different modes of stimulation. Our previous study demonstrated differences in the contractility of various regions (from the caput to the cauda) of rat epididymis in response to adrenergic drugs, indicating the uneven distribution of the smooth muscle and adrenoceptors (Pholpramool and Triphrom, 1984; Pholpramool et al., 1984). The site of micropuncture (site 6 ) in the present study corresponds to the proximal cauda epididymidis, at least $10 \mathrm{~cm}$ from the epididymal vas deferens junction (G. Chaturapanich, S. Maythaarttaphong and C. Pholpramool, unpublished), whereas the segment used by Ventura and Pennefather $(1991,1994)$ was more proximal, $4-5 \mathrm{~cm}$ from the vas deferens. With regard to the mode of stimulation, in the present study agonists were used at pharmacological doses that may overwhelm the effect of neurotransmitters released from nerve terminals. In contrast, the effects of electrical field stimulation used by Ventura and Pennefather depended on both the release of neurotransmitter and the excitability of muscle membrane. As $\alpha_{2}$-adrenoceptors are also present on the postsynaptic site, especially at the extrajunctional region of smooth muscle membrane (Rang and Dale, 1987), they would not be easily discerned by nerve stimulation. In addition, the failure to abolish completely contractions by the maximal doses of prazosin and $\alpha, \beta$-methylene ATP would argue against the absence of $\alpha_{2}$-adrenoceptor in the previous study (Ventura and Pennefather, 1991). However, the failure to demonstrate $\left[{ }^{3} \mathrm{H}\right]$ rauwolscine-binding sites by the same authors could not be explained. Therefore, it is proposed that the proximal cauda epididymidis of rats contains both $\alpha_{1}$ - and $\alpha_{2^{-}}$ adrenoceptors. The sites of the latter are probably on both nerve terminals and smooth muscle membrane. Further studies are required to determine the location of $\alpha_{2^{-}}$ adrenoceptors in the rat epididymis.

This work was supported by the Faculty of Science and the Faculty of Graduate Studies, Mahidol University. The authors are grateful to $\mathrm{S}$. Jaroonsuck for his technical service of the servonulling pressure system and C. Sapeeya for typing the manuscript.

\section{References}

Cooper TG (1986) Maturation of spermatozoa in the epididymis. In The Epididymis, Sperm Maturation and Fertilisation pp 1-5 Ed. TG Cooper. Springer Verlag, Berlin

Cummins JM (1976) Effects of epididymal occlusion on sperm maturation in the hamster Journal of Experimental Zoology 197 187-190

Din-Udom A, Sujarit S and Pholpramool C (1985) Short-term effect of androgen deprivation on intraluminal pressure and contractility of the rat epididymis Journal of Reproduction and Fertility 73 405-410

El-Badawi A and Schenk EA (1967) The distribution of cholinergic and adrenergic nerves in the mammalian epididymis: a comparative histochemical study American Journal of Anatomy 121 1-14

Haynes JM and Hill SJ (1996) Alpha-adrenoceptor mediated responses of the cauda epididymis of the guinea-pig British Journal of Pharmacology 119 1203-1210

Hib J (1976) Effect of autonomic drugs on epididymal contractions Fertility and Sterility 27 951-956

Hib J and Ponzio RO (1977) Effect of efferent duct ligation, gonadectomy and testosterone replacement on epididymal contractility in the rat Journal of Reproduction and Fertility 50 327-329

Hinton BT, Dott HM and Setchell BP (1979) Measurement of the motility of rat spermatozoa collected by micropuncture from the testis and from different regions along the epididymis Journal of Reproduction and Fertility 55 167-172

Hodson N (1970) The nerves of the testis, epididymis and scrotum. In The Testis pp 47-99 Eds AD Johnson, WR Gomes and NL Vandemark. Academic Press, London

Koefoed-Johnsen HH (1960) Influence of ejaculation frequency on the time required for sperm formation and epididymal passage in the bull Nature London 185 49-50

Laitinen L and Talo A (1981) Effects of adrenergic and cholinergic drugs on electrical and mechanical activities of the rat cauda epididymidis in vitro. Journal of Reproduction and Fertility 63 205-209

Meistrich ML, Hughes TJ and Bruce WR (1975) Alteration of epididymal sperm transport and maturation in mice by oestrogen and testosterone Nature London 258 145-147

Pholpramool C and Triphrom N (1984) Effect of cholinergic and adrenergic drugs on intraluminal pressure and contractility of the rat testis and epididymis in vivo. Journal of Reproduction and Fertility 71 181-188

Pholpramool C, Triphrom N and Din-Udom A (1984) Intraluminal pressures in the seminiferous tubules and in different regions of the epididymis in the rat Journal of Reproduction and Fertility $\mathbf{7 1}$ 173-179

Queiroz-Neto A and Ballejo G (1993) Alpha 1-adrenoceptor subtypes mediating the norepinephrine-induced contractile response in the rat vas deferens General Pharmacology 24 1149-1153

Rang HP and Dale MM (1987) Adrenergic transmission. In Pharmacology pp 146-176 Eds HP Rang and MM Dale. Churchill Livingstone, New York 
Ratnasooriya WD and Wadsworth RM (1990) Impairment of fertility of male rats with prazosin Contraception $41441-447$

Ricker DD and Chang TSK (1996) Neuronal input from the inferior mesenteric ganglion (IMG) affects sperm transport within the rat cauda epididymis International Journal of Andrology 19 371-376

Ricker DD, Crone JK, Chamness, SL, Klinefelter GR and Chang TSK (1997) Partial sympathetic denervation of the rat epididymis permits fertilization but inhibits embryo development Journal of Andrology 18 131-138

Sujarit S and Pholpramool C (1985) Enhancement of sperm transport through the rat epididymis after castration Journal of Reproduction and Fertility 74 497-502

Ventura S and Pennefather JN (1991) Sympathetic co-transmission to the cauda epididymis of the rat: characterization of post junctional adrenoceptor and purinoceptor British Journal of Pharmacology 102 540-544

Ventura S and Pennefather JN (1994) Alpha 2-adrenoceptor binding sites vary along the length of the male reproductive tract: a possible basis for the regional variation in response to field stimulation European Journal of Pharmacology 254 167-173

Received 9 July 2001.

First decision 21 January 2002.

Revised manuscript received 28 May 2002.

Accepted 2 September 2002. 